\title{
The Impact of Organizational Silence on a Sustainable Competitive Advantage: A Case Study of the Electrical Industries Company
}

\author{
Dr. Muayad Abdulkareem Shakir Al-naqeeb \\ Dr. Imad Khaleel Ismael \\ Faculty of Business Administration, \\ Al-Mamoun University College, \\ 14 Ramadan St, Baghdad, Iraq
}

DOI: https://doi.org/10.36941/mjss-2021-0o16

Abstract

This study seeks to analyze the factors causing organizational silence and the impact of this on the sustainable competitive advantage of organizations, The researchers used the descriptive approach, being the best approach from the researchers' point of view, to clarify the relationship between the research variables and the achievement of the study objectives, The Electric Industries Company was chosen to understand the reality of organizational silence and analyze what is required in order to make the necessary recommendations that can contribute to sustaining the company's competitive advantage and reducing the phenomenon of organizational silence and its effects. The results of research confirmed the inverse correlation between organizational silence and the sustainable competitive advantage, also that the organizational silence has a negative effect on the sustainable competitive advantage.

Keywords: organizational silence, sustainable competitive advantage, Cost Leadership Strategy, Product Differentiation Strategy, Focus Strategy

\section{Introduction}

Organizational silence in general revolves around the unwillingness of workers in the organization to disclose the organizational issues and problems related to the organization's performance and work, and the reason for this may be due to their fear of the reactions of managers, or from the negative reactions that may occur result of their expressing what they carry From ideas and opinions. This may greatly affect the competitive advantage of the organization, especially in light of the intensification of competition that we are experiencing today in light of the openness of global markets due to the expansion of the field of trade across international borders and the large number of competitors. Due to the novelty of this term in the administrative aspect, researchers have chosen it to be the subject of this study.

\section{$1.1 \quad$ Research Problem}

Organizational silence in organizations is considered a negative phenomenon, especially if we know 
that employees represent the basis of the administrative process. No organization, regardless of its type or competence, can achieve the goals to which it aspires unless it depends on capable and qualified employees so that they can be able to help the organization to reach its desired goals. This is because the ability of the organization to achieve its goals or be successful does not depend on the efforts of managers only, regardless of their levels and capabilities; employees play a key role in that. It should be noted here that these individuals or employees may differ. On the one hand, some of them are opposed to the wrong methods and work procedures in the organization in which they work. On the other hand, others are calm and do not complain about their boss or coworkers. This is the reality of many of our organizations, which means in this case that organizational silence occurs, leading to many negative phenomena such as low levels of organizational loyalty, organizational terrorism, and decline in the satisfaction and morale of the employees, which has negative effects on the organization. Hence, we set out to study organizational silence because of the impact of organizational silence on the competitive advantage. Accordingly, the research problem centered mainly on defining organizational silence and its effect on the sustainable competitive advantage, which can be studied through the following questions:

1. What is the level of organizational silence in the studied organization?

2. What is the level of the sustainable competitive advantage?

3. What are the reasons for the organizational silence prevailing in the organization in order of perceived importance from the point of view of the research sample?

4. What is the relationship between organizational silence and its causes that are included in the research and the sustainable competitive advantage?

5. To what extent does organizational silence affect the sustainable competitive advantage?

\subsection{Research Hypotheses}

The research is based on the following main hypothesis and sub-hypotheses:

The first main hypothesis: There is a significant inverse correlation between the causes of organizational silence and the sustainable competitive advantage. Based on this main hypothesis, the following sub-hypotheses were developed:

The first sub-hypothesis: There is a significant inverse correlation between the causes of organizational silence and the cost leadership strategy.

The second sub-hypothesis: There is a significant inverse correlation between the causes of organizational silence and the product differentiation strategy.

The third sub-hypothesis: There is a significant inverse correlation between the causes of organizational silence and the focus strategy.

The second main hypothesis: Organizational silence (and its causes) has a significant adverse effect on the sustainable competitive advantage. Based on this main hypothesis, the following subhypotheses were developed:

The first sub-hypothesis: Organizational silence (and its causes) has a significant adverse effect on the cost leadership strategy.

The second sub-hypothesis: Organizational silence (and its causes) has a significant adverse effect on the product differentiation strategy.

The third sub-hypothesis: Organizational silence (and its causes) has a significant adverse effect on the focus strategy.

\section{Theoretical Framework}

\subsection{Organizational Silence}

Organizational silence is considered one of the subjects that has a clear impact on the various 
development processes and challenges that face organizations because organizational silence has a significant impact on efficiency and effectiveness. There has been a growing interest in this subject because it is related to employee behavior, especially negative behavior, as it represents one of the important problems of the process of development and progress. Human resources are the key players in change and cooperation in any organization. For this reason, an organization success and improve it efficiency mainly depend on the human capital. Now a days the organizations adapt a new vision and change it demand from the employees, that involve a constant share of opinions of the employee, their beliefs, knowledge, and new experience in an ideal environment in the organization. Unfortunately, employees may have important ideas for the organization in some case but they did not express their ideas, which creating problems for the organizations. Lack of information is considered an important reasons in which failure to change management programs, which Morrison and Milliken called this situation as organizational silence. (Shirvani et al., 2019).

The concepts and definitions related to this subject were different based on different points of view. In this study, we will try to address some of them in order to find the common elements between them so as to use them in our research. Organizational silence is not individual behavior, but it is rather spread across all parts of the organization. It is the general attitude of individuals or workers towards organizational issues. Although silence is a process that can negatively affect parts of the organization and it is the common choice of members of the organization, we notice that all research indicated the value and importance of upward information flow. In other words, organizational silence is not always considered a passive attitude because it may be a conscious internal activity and may be purposeful when the individual is aware of his silence. He also knows that he has a lot of options regarding the current situation, but he remains silent because he feels unable to change it. This is expressed by a degree of awareness and acceptance, which is considered part of the employee's commitment. Employee silence may be very dangerous for the organization, as this silence can lead to lack of interest among the employees. Uninterested employees are indifferent to the values of their organizations, and this can cause poor employee performance. In this way, this silent employee causes the organization and its employees to lose a whole lot (Deniz, 2013).

Employee silence is still a relatively new topic. It occurs when the employees, whether intentionally or unintentionally, refrain from giving valuable information about their organizations. Usually this developed if the employees fail to communicate to supervisors or managers. Employees in organizations are often faced either to express or hide their thoughts, opinions, and concerns. Unfortunately, in many situations, they choose the silence which is the safes option, by withholding input that may have a valuable effect to others or thoughts that they wish they could express (Fapohunda, 2016).

\subsubsection{Definition of Organizational Silence}

Many researchers and scholars in the field of management tried to define organizational silence using various models, each according to his opinion and view of the topic. We will deal with some of these definitions that are relevant to our research without going into details. Organizational silence is defined as the intentional withholding of questions, ideas, opinions, and information by employees concerning issues related to their work or organization. It is seen as the staff's inability to express their opinions and refraining from talking about work-related problems and issues (Alheet et al., 2019). It was also defined as the conditions in which employees withhold information that is potentially beneficial or valuable to the organization in which they work (Fapohunda et al., 2016). In light of the above definitions, we can formulate the following procedural definition of organizational silence to serve the purposes of our current research. Organizational silence refers to the situation in which the employee refrains from or is hesitant about talking about matters related to work for fear that this will be misinterpreted by his boss, which may negatively affect the relationship with his coworkers. Organizational silence is also defined as "a collective phenomenon in which employees withhold their opinions and concerns regarding potential organizational problems" (Alqarni, 2020). 


\subsubsection{Reasons of Organizational Silence}

Many specialists tried to point out the reasons that lead to the phenomenon of organizational silence, as a result of its negative effects on the organization and the employees which include obstructing and delaying the communication process in addition to poor organizational performance. New management techniques pay special attention the continuous development of the knowledge, skills, and capabilities of the employees and to providing mutual benefits for both the employees and the organization. In fact, the organizational voice can be a powerful source of organizational change. However, research shows that, despite their self-confidence, employees are reluctant to express their opinions. They believe that engaging in discussions and speaking openly is risky. Therefore, it was found that employees in general are not willing to speak. At this point, we are faced with the concept of organizational silence (Erigüç et al., 2014).

As innovation stops, ethics are in decline, and defective products increase, employees do not care about the quality of their work over time. Therefore, organizational silence is harmful not only to the employees, but also to the organization and to individuals. Some have noted that the most common and widespread causes are the organizational climate, the organizational culture, unfair treatment, lack of confidence, lack of experience, bias, fear of isolation, and undermining relationships (Jalilian \& Batmani, 2014; Wynen et al., 2019). Thus, we chose four of these reasons for our research based on the instrument we used, taking into consideration the research setting and sample:

- Fear of undermining relationships

Employees are aware that there are weaknesses in the organizational structure and the processes that take place in the organization, but they are reluctant to express their views and suggestions because they believe that they will not be taken into consideration on the one hand or because they are afraid of losing their relationships with colleagues on the other hand (Morrison, 2014).

- Work-related concerns

Some workers intentionally refrain from mentioning their problems because they fear that others may believe that they are troublemakers, which may lead them to lose promotion opportunities or be subjected to ill-treatment and consequently be treated unfairly by the senior management, so they choose silence (Gulluce et al., 2016).

- Organizational and administrative reasons

These are mainly related to the decision-making process in the organization where the manager is unable to make a proper decision, thus leading to reduced organizational effectiveness and poor organizational performance. These negative phenomena occur as a result of employee silence as they do not talk about them or discuss them for fear of consequences as they believe that there will be negative reactions (Jalilian \& Batmani, 2014).

- Low Self-Esteem

The ability of an individual to express himself without fear or hesitation depends on the level of his self-esteem. People with low self-esteem tend to protect themselves more. Speaking openly may sometimes give the person status, but in case of failure, there may negative consequences. Individuals with low self-esteem avoid expressing themselves and providing their views because they are afraid of taking risks (Akin \& Ulusoy, 2016).

\subsection{Sustainable Competitive Advantage}

The business environment now a days becoming very competitive. With technological availability, it become easier to start a business, allows conducting business online, and gaining international customers in foreign markets. The growth of online retail is a good example of this. Despite these facilities the competition and activity make it harder to be unique. The best way is development of 
sustainable competitive advantage that sets you apart from your competitors. The sustainable competitive advantage is considered as a key to business success.

The sustainable competitive advantage making the business value of long-term and is what costumers will place the most value on when looking to acquire a business. Without it, there will be significant risks to the company, its future, and profits (Peskett, 2018).

The sustainable competitive advantage was defined as the continuity of benefits and the application of unique value creation strategies asynchronously with potential competitors who are not able to copy these advantages in any way (Alalie, 2018). Also, sustainable performance plays a major role in corporate sustainability, especially medium and small enterprises (Haseeb et al., 2019). After reviewing some of the concepts that researchers addressed in relation to the sustainable competitive advantage, it can be seen that, despite their different viewpoints, they are simply stressing that it is the ability to meet the requirements of the clients dealing with it or looking at it through increasing its market share, its ability to exploit its internal resources in the right direction, or the rare characteristics it has compared to others. Accordingly, based on these definitions, it can be said that the sustainable competitive advantage is the state of creativity and excellence that distinguishes the organization from its counterparts through the good investment of its rare resources which is difficult for others to imitate, thus ensuring its survival and development.

According to Michael Porter, there are three basic strategies through which companies can achieve a sustainable competitive advantage, and these three strategies will be included in the current research as dimensions to measure the sustainable competitive advantage. These strategies are:

\subsubsection{Cost Leadership Strategy}

This strategy is related to reducing the costs of the product or service to the lowest possible level without affecting production rates or the level of quality of that good or service. This can be achieved by enhancing employee experience and development in order to make the best investment of the organization's available resources. This is in addition to emphasizing production efficiency in a way that achieves the highest levels of productivity, the lowest possible costs, and the investment of machinery and manufacturing capabilities with the highest production capabilities and the lowest possible costs, whether at the level of production, expenditures, or after-sale service advertisements. In other words, this is a strategy that requires the company to produce the least expensive product in order to earn above-average profits in a way that increases the competitive capabilities of the organization.

Cost leadership is about gaining cost advantage by producing goods and services at lower cost than competitors. Companies could make forward, backward and horizontal combination of strategies to gain cost advantage (Kaliappen \& Hilman, 2016).

\subsubsection{Product Differentiation Strategy}

Product differentiation meets the customer's unique need through customizing the product or service, enable the organization commanding a premium price in order to increase its market share. The differentiation strategy is established effectively if the business provides a unique or superior value to a customer through product quality, features, or even after-sales support. Quality may be real or perceived based on fashion, brand name, or image. Companies that use a differentiation strategy can give their products higher value based on product characteristics, delivery system, quality of service, or distribution channels. The differentiation strategy appeals to consumers who want a unique product and who are willing to pay a higher price (Kaliappen \& Hilman, 2016).

\subsubsection{Focus Strategy}

The focus strategy aims to focus on a market segment and not the entire market. Companies that use focus strategies must be able to define their target market segment and assess the needs and desires 
of buyers in that segment so as to meet them better than any other competitor (Bordean et al., 2010). 2.2.4 Analysis of the Results of Descriptive Statistics and Hypothesis Testing

The empirical study is based on presenting and discussing the results of the analysis of the descriptive statistics of the variables at the level of their dimensions and items first, then discussing the results of the analysis related to testing the research hypotheses according to the outputs of three statistical tools used for this purpose, namely (Excel 2016), (SPSS24), and (AMOS24). Consequently, this part was divided into two sections; the first section was devoted to discussing the results of the descriptive statistics, while the second section was concerned with discussing the results of hypothesis testing, as indicated below:

\section{Methodology}

The researchers used the descriptive approach in the theoretical side of the study, as it is the best approach to measure the studied phenomenon and to find the relationship between the research variables, With the assistance of the analytical method complementing it.

As for the practical side of the research, the researchers used the field survey method. By distributing the questionnaire form prepared for this purpose to the research sample, and then the researchers analyzed the data and processed it statistically with the help of the statistical application (SPSS), And some other statistical means.

\subsection{Research sample}

A research sample consisting of (150) people working in the General Company for Electrical Industries in Baghdad was chosen from both sexes. (15) questionnaires were excluded from them due to the inaccuracy of the answers in them, to the questionnaire questions prepared by the researchers, so that the total correct answers (135) answers, which is the final sample from which the phenomenon in question was measured, of which (47) females and (88) males.

\subsection{Research Objectives}

The research set out to achieve the following objectives:

- Identify the research variables.

- Identify the reasons that make the employees resort to organizational silence in the workplace.

- Determine the level of both organizational silence and the sustainable competitive advantage in the studied company.

- Demonstrate the relationship between organizational silence and the sustainable competitive advantage.

\section{Results of Descriptive Statistics}

The descriptive statistics tools used to measure the research variables were distributed among a number of measures of central tendency and dispersion represented by the arithmetic mean according to which the response levels were determined by dividing them into five levels after dividing the range of the five-level scale, which is (4), by the number of categories of the scale, which is $(5)$, thus adding the result (o.8o) to the minimum of the scale in the rest of the items according to the following division and the resulting response levels:

Very low $(1-1.80)$, low $(1.81-2.6)$, moderate $(2.61-3.40)$, high $(3.41-4.20)$, very high $(4.21-5)$

As for the measures of dispersion, they included the standard deviation and the coefficient of variation for the purpose of determining the relative importance of each item in light of the 
coefficient of variation which measures the extent of agreement in the opinions of the sample in relation to an item or a specific dimension when the value of the coefficient of variation is low. Based on this, the results of the analysis are presented for the independent variable which is organizational silence followed by the dependent variable which is the sustainable competitive advantage:

\subsection{Organizational Silence}

This variable was expressed in this study by four main dimensions (fear of undermining relationships, work-related concerns, organizational and administrative reasons, low self-esteem) as shown in the results of the descriptive analysis of each of them (at the level of the dimensions and their items) in the following items and according to their arithmetic means, standard deviations, and coefficients of variation, in addition to determining the levels of response and their relative importance.

Table (1): The descriptive statistics of the dimensions of "organizational silence"

\begin{tabular}{|c|c|c|c|c|c|c|}
\hline No. & $\frac{\text { Descriptive statistics tools }}{\text { Items }}$ & $\begin{array}{c}\text { Arithmetic } \\
\text { mean }\end{array}$ & \begin{tabular}{|l|} 
Standard \\
deviation
\end{tabular} & \begin{tabular}{|l|}
$\begin{array}{l}\text { Coefficient } \\
\text { of variation }\end{array}$ \\
\end{tabular} & \begin{tabular}{|c|} 
Level of \\
response
\end{tabular} & \begin{tabular}{|c|} 
Relative \\
importance
\end{tabular} \\
\hline \multicolumn{7}{|c|}{ a. Fear of undermining relationships } \\
\hline 1 & $\begin{array}{l}\text { The fear of losing favor with my direct superior leads me } \\
\text { to silence. }\end{array}$ & 3.3836 & 1.138 & 0.336 & moderate & 3 \\
\hline 2 & $\begin{array}{l}\text { My colleagues have a negative opinion of me when I talk } \\
\text { about a problem. }\end{array}$ & 2.5890 & 1.152 & 0.445 & low & 4 \\
\hline 3 & $\begin{array}{l}\text { I fear that my colleagues would not support me when I } \\
\text { talk about a problem. }\end{array}$ & 3.2466 & 1.051 & 0.323 & moderate & 2 \\
\hline 4 & $\begin{array}{l}\text { If I talk about problems, it could affect my relationship } \\
\text { with others. }\end{array}$ & 3.6438 & 0.977 & 0.268 & high & 1 \\
\hline & Overall mean of the dimension & 3.2158 & 0.764 & 0.237 & moderate & \\
\hline \multicolumn{7}{|c|}{ b. Work-related concerns } \\
\hline 1 & $\begin{array}{l}\text { My fear of losing my job or the position I occupy prevents } \\
\text { me from speaking about a problem or discussing it. }\end{array}$ & 3.3973 & 1.163 & 0.342 & moderate & 2 \\
\hline 2 & $\begin{array}{l}\text { I am reluctant to raise any issue for fear of hatred and } \\
\text { retaliation by direct superiors. }\end{array}$ & 3.4658 & 1.014 & 0.292 & high & 1 \\
\hline 3 & $\begin{array}{l}\text { I am subjected to abuse and oppression as a result of } \\
\text { speaking about a problem. }\end{array}$ & 2.9452 & 1.078 & 0.366 & moderate & 4 \\
\hline 4 & Talking about a problem may affect my position. & 3.1370 & 1.109 & 0.353 & moderate & 3 \\
\hline & Overall mean of the dimension & 3.2363 & 0.714 & 0.220 & moderate & \\
\hline \multicolumn{7}{|c|}{ c. Organizational and administrative reasons } \\
\hline 1 & $\begin{array}{l}\text { There is no formal mechanism in the company that allows } \\
\text { us to talk about problems. }\end{array}$ & 3.2329 & 1.034 & 0.319 & moderate & 2 \\
\hline 2 & $\begin{array}{l}\text { The culture adopted here does not allow freedom of } \\
\text { speech in the workplace. }\end{array}$ & 3.1096 & 1.021 & 0.328 & moderate & 3 \\
\hline 3 & $\begin{array}{l}\text { The prevailing hierarchy prevents me from expressing my } \\
\text { thoughts. }\end{array}$ & 3.0000 & 1.027 & 0.342 & moderate & 4 \\
\hline 4 & $\begin{array}{l}\text { I do not talk about my problems because I have no } \\
\text { confidence in my managers. }\end{array}$ & 3.1507 & 0.923 & 0.292 & moderate & 1 \\
\hline & Overall mean of the dimension & 3.1233 & 0.772 & 0.247 & moderate & \\
\hline \multicolumn{7}{|c|}{ d. Low self-esteem } \\
\hline 1 & Work and workplace problems are none of my business. & 3.3699 & 0.905 & 0.268 & moderate & 1 \\
\hline 2 & $\begin{array}{l}\text { My thoughts have no importance because of my lower- } \\
\text { level job. }\end{array}$ & 3.2466 & 0.939 & 0.289 & moderate & 3 \\
\hline 3 & Lack of experience prevents me from speaking at work. & 3.3973 & 0.982 & 0.289 & moderate & 2 \\
\hline 4 & $\begin{array}{l}\text { I do not have enough experience to prepare a proposal or } \\
\text { present a problem. }\end{array}$ & 3.2055 & 0.971 & 0.302 & moderate & 4 \\
\hline & Overall mean of the dimension & 3.3048 & 0.669 & 0.202 & moderate & \\
\hline
\end{tabular}


The results of the descriptive analysis of the dimension fear of undermining relationships of in Table (1) indicate that the fourth item (If I talk about problems, it could affect my relationship with others.) had the highest arithmetic mean (3.6438) with a standard deviation (0.977), which is the lowest compared to rest of the items of this dimension. These results were reflected in a decrease in the coefficient of variation (.268), making it rank first in terms of its relative importance compared to the rest of the items of the dimension and with a high level of response. All these results reflect the high agreement between the members of the sample about the importance of this item. On the other hand, the second item (My colleagues have a negative opinion of me when I talk about a problem.) had the lowest arithmetic mean (2.589) with a standard deviation (1.152), which is the highest compared to the other items. It ranked fourth in terms of relative importance with a coefficient of variation (.445) as a result of the relative decrease in the arithmetic mean and the response level. The overall mean of the dimension (Fear of undermining relationships) was (3.2158) and the standard deviation was (o.764), and this was reflected in the coefficient of variation which was (0.237). This points to the organizational silence reflected by the high level of employees' responses to the items represented by the fear of losing favor with direct superiors and the fear of the colleagues' bad opinion and lack of support when talking about a problem related to work.

As for the second reason, which is work-related concerns, the results of analysis shown in Table (1) indicate that the second item (I am reluctant to raise any issue for fear of hatred and retaliation by direct superiors.) had highest arithmetic mean (3.4658) with a standard deviation (1.014), which is the lowest compared to the rest of the items of this dimension. As for the rest of the items, the arithmetic means, the standard deviations, and the coefficient of variation varied according to the same pattern. This is confirmed by the results indicated in the table; the overall mean of the dimension was (3.2363), with a standard deviation (0.714) and a coefficient of variation (0.220). These results point to the level of the reasons of organizational silence as indicated by the items.

As for the third reason of organizational silence which is administrative and organizational reasons, the results of the responses of the sample members in relation to the items of this dimension were similar. The means of the dimension was (3.1233), the standard deviation was (0.772), and the coefficient of variation was (0.247). This indicates an agreement in the opinions of the sample in relation to the importance of the items of the dimension of administrative and organizational reasons. These items point to the absence of a formal environment that allows the employees to express their opinions and ideas and the hierarchy that prevents the employees from doing this, in addition to the employees' lack of confidence in the managers.

Finally, the reasons related to low self-esteem confirm the results indicated in the same table. The overall mean of the dimension was (3.3048), the standard deviation was (0.669), and the coefficient of variation was (0.202). In the same vein, the results indicate an agreement in the opinions of the members of the sample in relation to the items of the dimension of low self-esteem. These items point to the lack of opportunities in addition to the employee's lack of experience, which makes him reluctant to present his views and ideas to his superiors. This results in organizational silence.

\subsection{Sustainable Competitive Advantage}

This variable consisted of three main dimensions (cost leadership strategy, product differentiation strategy, and focus strategy). The results of the analysis of the descriptive statistics are presented in the following table, and then explained below: 
Table (2): The descriptive statistics of the dimensions of "sustainable competitive advantage"

\begin{tabular}{|c|c|c|c|c|c|c|}
\hline No. & $\frac{\text { Descriptive statistics tools }}{\text { Items }}$ & $\begin{array}{c}\text { Arithmetic } \\
\text { mean }\end{array}$ & $\begin{array}{l}\text { Standard } \\
\text { deviation }\end{array}$ & $\begin{array}{l}\text { Coefficient } \\
\text { of variation }\end{array}$ & $\begin{array}{l}\text { Level of } \\
\text { response }\end{array}$ & \begin{tabular}{|c|} 
Relative \\
importance
\end{tabular} \\
\hline \multicolumn{7}{|c|}{ a. Cost leadership strategy } \\
\hline 1 & $\begin{array}{l}\text { Our organization gives great attention to } \\
\text { increasing the productivity of workers in order to } \\
\text { reduce costs without causing environmental } \\
\text { damage. }\end{array}$ & $3 \cdot 5751$ & 0.918 & 0.298 & moderate & 2 \\
\hline 2 & $\begin{array}{l}\text { Our company is concerned with controlling } \\
\text { expenses in order to save money continuously. }\end{array}$ & 3.0000 & 1.130 & 0.376 & moderate & 5 \\
\hline 3 & $\begin{array}{l}\text { Our company depends on obtaining price } \\
\text { advantages in order to reduce costs while } \\
\text { conserving sustainable materials. }\end{array}$ & 2.8630 & 1.004 & 0.350 & moderate & 3 \\
\hline 4 & $\begin{array}{l}\text { Our company depends on product imitation to } \\
\text { save the costs of innovation. }\end{array}$ & 2.7671 & 0.993 & 0.358 & moderate & 4 \\
\hline 5 & $\begin{array}{l}\text { Our company depends on high volume } \\
\text { technologies and the optimized investment of its } \\
\text { resources. }\end{array}$ & 3.0685 & 1.004 & 0.327 & moderate & 1 \\
\hline & Overall mean of the dimension & 2.9699 & 0.685 & 0.230 & moderate & \\
\hline \multicolumn{7}{|c|}{ b. Product differentiation strategy } \\
\hline 1 & $\begin{array}{l}\text { Our company has accurate inspection and control } \\
\text { devices that prevent errors. }\end{array}$ & 3.3562 & 0.903 & 0.269 & moderate & 2 \\
\hline 2 & $\begin{array}{l}\text { Our company is constantly entering new markets } \\
\text { that are difficult for competitors to reach. }\end{array}$ & 3.2329 & 0.935 & 0.289 & moderate & 4 \\
\hline 3 & $\begin{array}{l}\text { Our company provides good products that } \\
\text { guarantee retaining existing customers and } \\
\text { winning new customers. }\end{array}$ & 3.1507 & 0.793 & 0.251 & moderate & 1 \\
\hline 4 & $\begin{array}{l}\text { Our company has very advanced production } \\
\text { technologies and is better than its competitors. }\end{array}$ & 3.4247 & 0.956 & 0.279 & high & 3 \\
\hline 5 & $\begin{array}{l}\text { Our company constantly provides products with } \\
\text { new formulas and technologies that re different } \\
\text { from the products of competitors. }\end{array}$ & 3.2603 & 0.957 & 0.293 & moderate & 5 \\
\hline & Overall mean of the dimension & 3.2849 & 0.629 & 0.191 & moderate & \\
\hline \multicolumn{7}{|c|}{ c. Focus strategy } \\
\hline 1 & $\begin{array}{l}\text { Our company has a distinct ability to penetrate a } \\
\text { specific targeted market with harmless products }\end{array}$ & 3.7123 & 0.935 & 0.251 & high & 1 \\
\hline 2 & $\begin{array}{l}\text { Our company focuses on marketing its products in } \\
\text { specific markets. }\end{array}$ & 3.0548 & 1.153 & 0.377 & moderate & 5 \\
\hline 3 & $\begin{array}{l}\text { Our company's systems are more effective for a } \\
\text { specific market when they penetrate targeted } \\
\text { markets with clean products. }\end{array}$ & 3.1233 & 0.881 & 0.282 & moderate & 2 \\
\hline 4 & $\begin{array}{l}\text { Our company has the ability to control costs when } \\
\text { serving specific customers. }\end{array}$ & $3 \cdot 5753$ & 1.053 & 0.294 & high & 3 \\
\hline 5 & $\begin{array}{l}\text { Our company adopts excellence philosophy by } \\
\text { penetrating a specific market segment. }\end{array}$ & 2.7671 & 0.950 & 0.343 & moderate & 4 \\
\hline & Overall mean of the dimension & 3.2466 & 0.692 & 0.213 & moderate & \\
\hline
\end{tabular}

This variable consisted of three strategies: cost leadership strategy, product differentiation strategy, and focus strategy. The results showing their level according to the answers of the members of the sample are presented in Table (2). The results of the cost leadership strategy revealed that the first item had the highest arithmetic mean (3.5751) with a standard deviation (0.298), and that the item 
that had the lowest arithmetic mean was the one related to competition in terms of the company's tendency to imitate products in order to save the costs of innovation. Its arithmetic mean was (2.7671) with a standard deviation (0.993) and a coefficient of variation (0.385).

As for the product differentiation strategy, its arithmetic means was (3.2849), with a standard deviation (o.629) and a coefficient of variation (o.191), and this indicates an agreement in the opinions of the sample on the items of this dimension.

Finally, regarding the focus strategy, it is clear that the level of responses of the sample members confirms that this strategy is adopted to a large extent, and this is evident from its arithmetic mean which was (3.2466), with a standard deviation (o.962) and a coefficient of variation (o.213). This indicates an agreement in the opinions of the sample on the items of this strategy, in addition to the decrease in the last item, which indicates the company's weak adoption of excellence philosophy by penetrating a specific market segment, as indicated in the above table.

In order to verify the correlations between the dimensions of the independent variable on the one hand and the effect of the dependent variable on the other hand so as to be able to test the assumed correlations between them, a correlation matrix was built for the dimensions of the variables as shown in Table (2). The correlation coefficients were not very high except for a few that exceeded (0.70). This confirms that there is no multicollinearity between those dimensions. In addition to this, all correlation coefficients were negative, and this confirms the inverse relationship between organizational silence and the sustainable competitive advantage. This was followed by testing these relationships in their inferential framework after employing multiple regression models to test the research hypotheses.

Table (3): Correlation matrix of the dimensions of the research variables

\begin{tabular}{|c|c|c|c|c|c|c|c|c|}
\hline Dimensions & & 1 & 2 & 3 & 4 & 5 & 6 & 7 \\
\hline \multirow{2}{*}{$\begin{array}{l}\text { Fear of undermining } \\
\text { relationships }\end{array}$} & \begin{tabular}{|l} 
Pearson \\
Correlation
\end{tabular} & 1 & $-0.554^{* *}$ & $-0.691^{* *}$ & $-0.633^{* *}$ & $-0.682^{* *}$ & $-0.648^{* *}$ & $-0.567^{* *}$ \\
\hline & Sig. (2-tailed) & & 0.000 & 0.000 & 0.000 & 0.000 & 0.000 & 0.000 \\
\hline \multirow[t]{2}{*}{ Work-related concerns } & $\begin{array}{l}\text { Pearson } \\
\text { Correlation }\end{array}$ & $0-.554^{* *}$ & 1 & $-0.550^{* *}$ & $-0.597^{* *}$ & $-0.577^{* *}$ & $-0.603^{* *}$ & $-0.674^{* *}$ \\
\hline & Sig. (2-tailed) & 0.000 & & 0.000 & 0.000 & 0.000 & 0.000 & 0.000 \\
\hline \multirow{2}{*}{$\begin{array}{l}\text { Administrative and } \\
\text { organizational reasons }\end{array}$} & $\begin{array}{l}\text { Pearson } \\
\text { Correlation }\end{array}$ & $-0.691^{* *}$ & $-0.550^{* *}$ & 1 & $-0.710^{* *}$ & $-0.838^{* *}$ & $-0.724^{* *}$ & $-0.665^{* *}$ \\
\hline & Sig. (2-tailed) & 0.000 & 0.000 & & 0.000 & 0.000 & 0.000 & 0.000 \\
\hline \multirow[t]{2}{*}{ Low self-esteem } & $\begin{array}{l}\text { Pearson } \\
\text { Correlation } \\
\end{array}$ & $-0.633^{* *}$ & $-0.597^{* *}$ & $-0.710^{* *}$ & 1 & $-0.700^{* *}$ & $-0.964^{* *}$ & $-0.643^{* *}$ \\
\hline & Sig. (2-tailed) & 0.000 & 0.000 & 0.000 & & 0.000 & 0.000 & 0.000 \\
\hline \multirow[t]{2}{*}{ Cost leadership strategy } & \begin{tabular}{|l} 
Pearson \\
Correlation \\
\end{tabular} & $-0.682^{* *}$ & $-0.577^{* *}$ & $-0.838^{* *}$ & $-0.700^{* *}$ & 1 & $-0.719^{* *}$ & $-0.632^{* *}$ \\
\hline & Sig. (2-tailed) & 0.000 & 0.000 & 0.000 & 0.000 & & 0.000 & 0.000 \\
\hline \multirow{2}{*}{$\begin{array}{l}\text { Product differentiation } \\
\text { strategy }\end{array}$} & \begin{tabular}{|l|} 
Pearson \\
Correlation \\
\end{tabular} & $-0.648^{* *}$ & $-0.603^{* *}$ & $-0.724^{* *}$ & $-0.964^{* *}$ & $-0.719^{* *}$ & 1 & $-0.642^{* *}$ \\
\hline & Sig. (2-tailed) & 0.000 & 0.000 & 0.000 & 0.000 & 0.000 & & 0.000 \\
\hline \multirow[t]{2}{*}{ Focus strategy } & $\begin{array}{l}\text { Pearson } \\
\text { Correlation } \\
\end{array}$ & $-0.567^{* *}$ & $-0.674^{* *}$ & $-0.665^{* *}$ & $-0.643^{* *}$ & $-0.632^{* *}$ & $-0.642^{* *}$ & 1 \\
\hline & Sig. (2-tailed) & 0.000 & 0.000 & 0.000 & 0.000 & 0.000 & 0.000 & \\
\hline
\end{tabular}

Table (3) shows the results of testing the research hypotheses as follows:

1. As for the first hypothesis which stated that is a significant inverse correlation between the causes of organizational silence represented by (fear of undermining relationships, workrelated concerns, administrative and organizational reasons, low self-esteem) and the cost leadership strategy, the results shown in Table (3) point to the validity of the hypothesis 
according to the correlation coefficients that were (o.682), (-0.577), (-0.838), and (0.799) respectively.

2. As for the second hypothesis, which stated that is a significant inverse correlation between the causes of organizational silence and the product differentiation strategy, the correlation coefficients shown in the table were (0.648), (-0.603), (-0.724), and (-0.964) respectively for the four dimensions of organizational silence and the product differentiation strategy which is one of the dimensions of the sustainable competitive advantage. These results prove that organizational silence negatively affects the sustainable competitive advantage.

3. Finally, the results shown in the table above point to the validity of the third hypothesis which stated that is a significant inverse correlation between organizational silence and the dependent variable, i.e. the sustainable competitive advantage, represented here by the focus strategy. The results were (0.567), (o.674), (-0.665), and (0.643) respectively for the dimensions of organizational silence and the focus strategy.

The above results confirm the validity of the research hypotheses and prove that organizational silence negatively affects the sustainable competitive advantage.

These results can be confirmed by testing the other hypotheses which are related to the negative effect of the dimensions of organizational silence and the dimensions of the sustainable competitive advantage through the regression coefficient.

Table (4): Results of testing the research hypotheses

\begin{tabular}{|c|c|c|c|c|c|c|}
\hline $\begin{array}{l}\text { Sign. } \\
\text { level }\end{array}$ & F-est & \begin{tabular}{|l|} 
Coeff. \\
of det.
\end{tabular} & \begin{tabular}{|l|} 
Sign. \\
level
\end{tabular} & t-test & Parameter\$ & Statistical results \\
\hline $\mathrm{P}>\mathrm{F}$ & $\mathrm{F}$ & $\mathrm{R}^{2}$ & $\mathrm{P}>|\mathrm{t}|$ & $|t|$ & B & Details \\
\hline \multirow{4}{*}{.000} & \multirow{4}{*}{48.64} & \multirow{4}{*}{0.74} & .046 & 2.06- & .13 & Fear of undermining relationships ---> Cost leadership strategy \\
\hline & & & .135 & -1.31 & .09 & Work-related concerns ---> Cost leadership strategy \\
\hline & & & .000 & -4.06 & .60 & Administrative and organizational reasons ---> Cost leadership strategy \\
\hline & & & .039 & $2.27^{-}$ & .14 & Low self-esteem ---> Cost leadership strategy \\
\hline \multirow[t]{4}{*}{.000} & $237 \cdot 3$ & 0.93 & .491 & $0.962-$ & .03 & Fear of undermining relationships ---> Product differentiation strategy \\
\hline & & & .533 & $1.23^{-}$ & .02 & Work-related concerns ---> Product differentiation strategy \\
\hline & & & .050 & $1.97^{-}$ & .06 & Administrative and organizational reasons ---> Product differentiation strategy \\
\hline & & & .000 & $5.12-$ & .89 & Low self-esteem ---> Product differentiation strategy \\
\hline \multirow[t]{4}{*}{.000} & 24.81 & 0.59 & 0.514 & $0.942-$ & .03 & Fear of undermining relationships ---> Focus strategy \\
\hline & & & o.oo & $3.89-$ & .38 & Work-related concerns ---> Focus strategy \\
\hline & & & 0.15 & $2.29-$ & .31 & Administrative and organizational reasons ---> Focus strategy \\
\hline & & & .047 & $1.99^{-}$ & -18 & Low self-esteem ---> Focus strategy \\
\hline
\end{tabular}

To determine the significance of the negative effect of organizational silence and its dimensions on the sustainable competitive advantage and its dimensions, the hypotheses put forward by the researchers were tested using the regression coefficient as shown in Table (4).

The first sub-hypothesis: The results of testing this hypothesis, which are presented in Table (4), pointed to the significance of the effect of all the dimensions of organizational silence on the cost leadership strategy which was first dimension of the dependent variable, i.e. the sustainable competitive advantage. The value of the beta coefficient for the dimension of fear of undermining relationships was $(\beta=.13, \mathrm{P}=0.046)$ and for the dimension of administrative and organizational reasons which had the strongest effect was $(\beta=.60, P=0.000)$, while it was $(\beta=.14, P=0.039)$ for the dimension of low self-esteem, excluding the dimension of work-related concerns which was not significant. The explanatory power of the model as a whole in light of the coefficient of determination was $\left(\mathrm{R}^{2}=.74\right)$, which was completely significant $(\mathrm{P}=0.000)$. This reflects the variance $(74 \%)$ explained by the dimensions of the organizational silence variable with its significant dimensions included in the studied organization. The remaining (26\%) is certainly influenced by other factors 
that may help in interpreting it, but they were not included in this test model.

The same applies to effect of the dimensions of organizational silence on the product differentiation strategy and its results shown in the same table, where $\mathrm{R}^{2}=0.93$, which was significant. This reflects the variance (93\%) explained by the dimensions of organizational silence. The remaining $(7 \%)$ is certainly influenced by other factors that were not included in this test model.

Finally, in the same way, the effect of the dimensions of organizational silence on the focus strategy is also evident as the significant adverse correlation is evident. This reflects the variance $(59 \%)$ explained by the dimensions of organizational silence. The remaining (41\%) is certainly influenced by other factors that were not included in this test model.

\section{Conclusions and Recommendations}

\subsection{Conclusions}

In light of the analysis of the practical framework of the research, it is possible to summarize the most important conclusions resulting from this analysis as follows:

1. The responses of the research sample confirmed the high level of dimensions of the research variables, i.e. organizational silence and the sustainable competitive advantage, as the arithmetic means of most items exceeded (3).

2. The results confirmed the validity of the hypotheses presented in this research about the inverse correlation between organizational silence and the sustainable competitive advantage.

3. The results also showed that organizational silence has a negative effect on the sustainable competitive advantage, as indicated by the results through the regression analysis of the two variables.

\subsection{Recommendations}

In light of the results of the practical analysis of each variable as indicated in the relevant tables, the most important recommendations are as follows:

1. It is important to pay attention to employee performance by giving them the opportunity to express their views through activating communication and designing the flexible organizational structure that increases communication between subordinates and their managers.

2. Boosting confidence in employees and encouraging them to present their opinions and problems in a way that reduces organizational silence.

3. Giving employees some responsibilities and allowing them to take part in decision-making while giving them the necessary powers to do so, thereby reducing isolation and, thus, organizational silence.

4. Holding continuous seminars for managers and employees in order to remove the barriers separating them, build a strong team spirit, and encourage teamwork so that efforts are geared towards developing a sustainable competitive advantage.

5. Working to encourage employees to address their problems in a way that promotes their common interests and the interests of the company too.

\section{References}

Akın, U. \& Ulusoy, T., (2016), The Relationship between Organizational Silence and Burnout among Academicians, International Journal of Higher Education Vol. 5, No. 2, p 3.

Alalie, H. M., (2018), The Challenges of Creating Sustainable Competitive Advantage in the Banking Industry in Iraq, World Journal of Business and Management, Vol. 4, No.2, p237. 
Alqarni, S. A. Y., (2020), How school climate predicts teachers' organizational silence, International Journal of Educational Administration and Policy Studies,Vol. 12(1), pp. 12-27, January-June, p3.

Bordean, O. N., et al, (2010) The Use of Michael Porter's Generic Strategies, in the Romanian Hotel Industry, International Journal of Trade, Economics and Finance, Vol. 1, No. 2, August, p 2.

Deniz, N., et.al. (2013), The Relationship between Employee Silence and Organizational Commitment in a Private Healthcare Company, 9th International Strategic Management Conference. p.3.

Erigüç, G., et.al. (2014), The Causes and Effects of the Organizational Silence: On Which Issues the Nurses Remain Silent? Journal of Management Economics and Business, Vol. 10, No. 22, p3.

Fathi, A., (2019) The Impact of the Causes of Organizational Silence Causal Factors on Self- Efficacy of Health Center Employees in the Jordanian Capital City (AMMAN), Academy of Strategic Management Journal, Volume 18, Issue 3, p. 2.

Gulluce. A. C., (2016), Analysis of Organizational Silence Attitudes of Hotel Operations' Employees by Structural Equation, European Scientific Journal July edition vol.12, pp. 7-8.

Haseeb, M., et al, (2019), Role of Social and Technological Challenges in Achieving a Sustainable Competitive Advantage and Sustainable Business Performance, Sustainability, 11, 3811.

Jalilian, R. F., (2015), Study of the Relationship Between the Organizational Silence \& The Employee' Performance (Case Study), Indian Journal of Fundamental and Applied Life Sciences: (Online) An Open Access, Online International Journal Available at:

Kaliappen, N., \& Hilman, H., (2016), Strategic match of cost leadership, competitor orientation and process innovation on performance, International Journal of Organizational \& Business Excellence, Vol. 1, Issue. 1, p3.

Morrison, E. W., (2014), Employee Voice and Silence, First published online as a Review in Advance on January 2.

Peskett, M., (2018), Five steps to get a sustainable competitive advantage, https://www.smartcompany.com.au /business-advice/strategy/five-steps-to-get-a-sustainable-competitive-advantag, p1.

Shirvani. M., (2019), Survey on the Relationship between Organizational Silence and Management Styles from the Viewpoint of Employees of TUMS General Hospitals 2016, Volume 3, Issue 1, March, p31.

Tinuke, F., (2016), Organizational Silence: Predictors \& Consequences Among University Academic Staff, International Journal for Research in Social Science and Humanities Research 83 Vol. 2 Issue.1 January, p. 2.

Wynen. J., et al. (2019) Just keep silent... Defensive silence as a reaction to successive structural reforms. 